\title{
Recent Developments in Targeting Eosinophil Accumulation as a Novel Therapeutic Approach for Asthma
}

\author{
Garry M. Walsh*, Alexander J. Robinson and Ping Wu
}

School of Medicine, Institute of Medical Sciences, University of Aberdeen, Scotland, Scotland, UK

\begin{abstract}
Current therapies for asthma are aimed at controlling disease symptoms and for the majority of patients inhaled glucocorticoid anti-inflammatory therapy is both effective and well-tolerated. However, concerns remain about the adverse effects of glucocorticoids while a subset of asthmatic patients remains symptomatic despite optimal treatment thereby creating a clear unmet medical need. There is considerable evidence that implicates eosinophils as important effector cells and immunomodulators in the inflammation characteristic of asthma. Numerous in vitro and animal studies have demonstrated essential roles for cell adhesion molecules in eosinophil adhesion and transendothelial migration including the selectins, ICAM-1, VCAM-1 together with many of the $\beta 1$ and $\beta 2$ integrins. A large body of evidence has also implicated several cytokines and chemokines in the selective recruitment of eosinophils to sites of asthmatic inflammation. Biopharmaceutical approaches have been used to identify inhibitory molecules that target key elements in the processes controlling eosinophil accumulation in asthma. This review will summarise the problems and successes regarding recent developments in therapeutic strategies aimed at reducing eosinophil-mediated inflammation in the asthmatic lung.
\end{abstract}

\section{INTRODUCTION}

Despite remarkable advances in diagnosis and long-term management, asthma remains a serious public health problem worldwide. Asthma pathology includes reversible airway obstruction, hyperresponsiveness of the airways to normally harmless stimuli and airway inflammation. The latter is characterised by infiltration of the airways by activated lymphocytes and eosinophils; damage to, and loss of, the bronchial epithelium; mast cell degranulation; mucous gland hyperplasia; and collagen deposition in the epithelial subbasement membrane area. Eosinophil accumulation in the lungs is a well defined feature of the inflammatory processes underlying allergic asthma even in mild forms of the disease [1]. Eosinophils contain cationic granule proteins, including major basic protein (MBP), eosinophil cationic protein $(\mathrm{ECP})$, eosinophil-derived neurotoxin (EDN), eosinophil peroxidase (EPO), together with membrane derived lipid mediators. They have also been shown to synthesise up to 28 cytokines, chemokines and growth factors, many of which are stored in their crystalloid granules. These well defined characteristics have led to the paradigm that eosinophils are major effector cells in the inflammatory process underlying much of the pathogenesis of asthma and other allergic diseases [2]. Eosinophils are also thought to contribute to the pathophysiology of airway remodelling primarily through the release of substances, particularly TGF $\beta$, involved in ECM deposition leading to sub-epithelial membrane thickening [3]. This view is further reinforced by a study showing that TGF $\beta 2$, secreted primarily by tissue eosinophils, is the predominant isoform in severe asthma and is associated with augmented profibrotic responses [4]. Eosinophil deficient

*Address correspondence to this author at the School of Medicine, Institute of Medical Sciences, University of Aberdeen, Aberdeen, Scotland, AB24 2ZD, UK; E-mail: g.m.walsh@abdn.ac.uk mouse models (PHIL), though yielding differing results, have provided strong support for eosinophil involvement in asthma $[5,6]$. It has been suggested that divergence between the models may have reflected differing mouse backgrounds i.e. Balb/c versus B6 mice. However, a recent study demonstrated that genetic ablation of eosinophils occurs in both $\mathrm{C} 57 \mathrm{BL} / 6 \mathrm{~J}$ or BALB/cJ mice. Furthermore, irrespective of background strain the loss of eosinophils resulted in the attenuation of key allergen-induced lung pathologies including decreased eosinophil numbers and reductions in airway hyper reactivity and remodelling [7].

From the forgoing it can be seen that eosinophils are usually considered as degranulating end-stage effector cells. However, in addition to their pro-inflammatory role in mediating asthmatic inflammation it is becoming apparent that eosinophils also play an important role in the orchestration of immune responses in the asthmatic lung. For example, eosinophils have a demonstrable role in presenting allergen to stimulate CD4+ T-helper (Th) cells [8, 9], while EDN has been shown to be a potent chemoattractant for dendritic cells thereby enhancing specific immunity by promoting antigen uptake, processing and presentation [10]. These findings have been recently extended to demonstrate that EDN activates myeloid dendritic cells through triggering of the Toll-like receptor (TLR)2-myeloid differentiation factor 88 signalling pathway that may result in preferential enhancement of antigen-specific Th2 immune responses [11]. Other recent evidence from mouse models of asthma suggests that eosinophils may be critical in the regulation of Th2 immune responses in the lung following allergen provocation. For example, ovalbumin (OVA)-sensitised/challenged eosinophil deficient PHIL mice had reduced airway levels of Th2 cytokines compared with to the OVA treated wild type mice. These findings correlated with a reduced ability to recruit effector T cells to the lungs of OVA-challenged PHIL mice 
suggesting an important role for eosinophils in this process [12].

A considerable body of research over many years has been aimed at of furthering our understanding of the interrelated events that control eosinophil accumulation in the asthmatic lung. This a complex process involving eosinophil maturation in and release from the bone marrow, adhesion to and transmigration through the post-capillary endothelium, followed by their chemotaxis to and activation/degranulation at inflammatory foci [13]. This review will summarise recent developments in therapeutic strategies aimed at preventing or blunting eosinophil accumulation in the asthmatic lung.

\section{TARGETING EOSINOPHIL ADHESION}

Asthma pathology is characterised by excessive leukocyte infiltration that leads to tissue injury. Cell adhesion molecules i.e. selectins, integrins and members of the immunoglobulin superfamily control leukocyte extravasation, migration within the interstitium, cellular activation, and tissue retention. Numerous animal studies have demonstrated essential roles for these cell adhesion molecules in lung inflammation including L-selectin, P-selectin, and E-selectin, ICAM-1, VCAM-1 together with many of the $\beta 1$ and $\beta 2$ integrins [14]. These families of adhesion molecules have therefore been under intense investigation to inform the development of novel therapeutics.

\section{Selectins}

Selectins are responsible for the early "rolling" adhesive events between leukocytes and the endothelial cells lining the post-capillary venules. The small molecule Bimosiamose (TBC1269) is a synthetic computer-designed antagonist, targeted against all three selectins, which has proven to be efficacious in mouse, rat, rabbit, guinea pig and sheep models of allergic asthma [15]. For example, in a sheep model of asthma inhaled TBC1269 potently inhibited allergic airway responses, histamine levels in BAL and tissue kallikrein and neutrophilic inflammation [16]. In patients with asthma a single intravenous dose of TBC1269 had only a minor effect on sputum eosinophils or inhaled allergen-induced late asthmatic reactions [17]. In contrast, inhaled TBC1269 significantly reduced antigen-induced late-phase asthmatic reactions by approximately $50 \%$ compared with placebo in mild asthmatic subjects [18]. Thus, the inhaled route of TBC1269 may offer advantages over systemic delivery in terms of both efficacy and safety. Since selectins are also vital in early adhesive neutrophil interactions with the endothelium TBC1269 may also prove an effective therapy for COPD.

\section{Integrins}

There is good evidence from animal models that $\alpha 4 \beta 1$ (VLA-4) is a viable drug target for asthma. Monoclonal antibodies $(\mathrm{mAb})$ against the $\alpha 4$ subunit of VLA-4 have proven efficacious in asthma models in five different species. For example, in a mouse model of asthma intravenously administered anti- $\alpha 4 \mathrm{mAb}$ eliminated eosinophilia but did not effect AHR. In contrast, when delivered intranasally, the $\mathrm{mAb}$ blocked both airway inflammation and AHR [19]. The small-molecule VLA-4 antagonist (2S)-3-(4-Dimethylcarbamoyloxyphenyl)-2-\{[(4R)-5,5-dimethyl-3-(1-methyl-1H-pyrazole-4sulfonyl)thiazolidine-4-carbonyl]amino $\}$ propionic acid (WAY103) was assessed for its effects on eosinophil VLA- 4-dependent functions, including adhesion, migration, respiratory burst, and degranulation. WAY103 inhibited eosinophil adhesion to VCAM-1, transendothelial migration and VCAM1 -stimulated eosinophil superoxide generation. However, it also enhanced cytokine-activated eosinophil-derived neurotoxin degranulation raising concerns that it might promote eosinophil activation in certain circumstances [20]. More recently, a potent and selective, small molecule VLA-4 inhibitor, (2S)-3-(2',5'-dichlorobiphenyl-4-yl)-2-(\{[1-(2-methoxybenzoyl)piperidin-3-yl]carbonyl $\}$ amino) propanoic acid, blocked VLA-4 dependent functions on a variety of cell types and also dose-dependently inhibited eosinophil infiltration by up to $80 \%$ in an air pouch mouse model [21]. Although other smallmolecule integrin $\alpha 4 \beta 1$ antagonists have been developed by pharmaceutical companies, the majority of these have proved to be ineffective in preventing the clinical symptoms of asthma. However, a recent clinical trial of an oral $\alpha 4 \beta 1$ antagonist valategrast demonstrated significant positive effects on lung function and rates of exacerbation in asthma patients who had their inhaled GC therapy withdrawn prior to treatment with valategrast [22].

\section{Pharmacological Inhibition of Eosinophil Adhesion Un- der Flow}

Another important aspect of inhibition of eosinophil accumulation has been the discovery of anti-inflammatory effects on their adhesion by drugs aimed at radically different pathways, namely $\mathrm{H} 1$ receptor antagonists and cysteinyl leukotriene receptor-1 (cysLT1R) antagonists. Histamine has a prominent and diverse role in the pathophysiology of allergic disease, therapeutic intervention is therefore commonly focused on blocking its interaction with H1-receptors. The H1histamine receptor is a heptahelical transmembrane molecule that transduces extracellular signals to intracellular second messenger systems via $\mathrm{G}$ proteins. $\mathrm{H1}$-antihistamines act as inverse agonists that combine with the H1-receptor, stabilising it in the inactive form and shifting the equilibrium toward the inactive state [23]. While effective in the treatment of allergic rhinitis, the use of first-generation antihistamines, such as chlorpheniramine and promethazine, was associated with unwanted side effects, particularly sedation and impaired psychomotor activity. In contrast, the second-generation histamine $\mathrm{H} 1$ receptor antagonists are highly effective and welltolerated treatments for allergic disease and are amongst the most frequently prescribed drugs in the world [24]. More recently, a number of novel antihistamines including fexofenadine, desloratadine and levocetirizine have been developed which are either metabolites of active drugs or enantiomers with improved potency, duration and onset of action together with increased predictability and safety.

Many antihistamines have additional anti-inflammatory effects that appear independent of $\mathrm{H} 1$ receptor antagonism, with particular effects on the accumulation and activation of diverse cells responsible for the manifestations of allergic disease [25]. For example levocetirizine, a potent, oral histamine $\mathrm{H} 1$ receptor antagonist for the symptomatic treatment of allergic rhinitis and chronic idiopathic urticaria, has been shown to have a number of anti-inflammatory effects on eosinophil accumulation, activation and mediator release [26]. In this regard, we have shown inhibition of eotaxininduced eosinophil transendothelial migration through monolayers of human dermal or lung microvascular endothe- 
lial cells in vitro by levocetirizine at concentrations equal to or lower than those achieved in the clinical setting [27]. We further demonstrated that physiologically-relevant concentrations of levocetirizine also inhibited both resting and GMCSF-stimulated eosinophil adhesion to vascular cell adhesion molecule-1 (VCAM-1) under flow conditions using a novel microflow system (Cellix VenaFlux ${ }^{\mathrm{TM}}$ ) as an in vitro model of the post-capillary venules [28]. Real time imaging revealed that the effect of levocetirizine on post-adhesion behaviour (detachment, flatness) contributed to its inhibitory action on eosinophil adhesion to rhVCAM-1. These in vitro observations are complimented by a randomised placebocontrolled clinical study that examined the effect of levocetirizine on symptoms, quality of life and nasal inflammatory parameters in patients with persistent rhinitis with or without asthma [29]. In addition to significantly improving both symptoms and quality of life measures over the two week study period, levocetirizine but not placebo decreased eosinophil and neutrophil numbers in nasal scrapings, suggesting an in vivo affect on the tissue accumulation of these granulocytes. Other studies have also demonstrated in vitro anti-inflammatory effects by levocetirizine at therapeutically meaningful drug concentrations. These include inhibition of eotaxin production by endothelial cells [30] or inhibition of ICAM-1 and major histocompatability complex (MHC) class I expression by IFN- $\gamma$-stimulated keratinocytes together with modulation of histamine-dependent release of GM-CSF and chemokines by these cells [31]. Furthermore, histamine-induced VCAM-1 expression by nasal polypderived human fibroblasts was also inhibited by levocetirizine [32]. In contrast, levocetirizine has no enhancing effect on the rate of apoptosis-induction in eosinophils either in the presence or absence of viability-enhancing cytokines [33]. These studies demonstrate in vitro anti-inflammatory effects by levocetirizine at low, physiologically-relevant concentrations on diverse cell types. However, an obvious question is the extent to which these anti-inflammatory properties for a given antihistamine have any clinical impact in addition to that given by H1-receptor blockade.

The cysteinyl leukotriene cysLT1 receptor (cysLT1R) antagonists are the first new class of anti-asthma drugs to be introduced in the last 30 years. Overall, they are less effective than steroids but some asthmatic subjects show a striking improvement and a steroid-sparing effect has been demonstrated [34-36]. The cysLT1R is present on the eosinophil cell surface [37] and may have a role in eosinophil adhesion, since stimulation of the receptor by leukotriene D4 was shown to upregulate eosinophil binding to recombinant human (rh) VCAM-1 [38]. cysLT1R antagonists also appear to have additional inhibitory effects on eosinophil adhesion. In this regard, montelukast [39, 40] and pranlukast [41] inhibited the transmigration of eosinophils across human endothelial umbilical vein endothelial cells (HUVEC) under static conditions. Antagonism of the cysLT1R also blocked $\beta 2-$ integrin avidity and $\beta 2$-integrin mediated eosinophil adhesion to ICAM-1 [42]. Other in vivo studies have shown that montelukast blocked plasma protein extravasation and eosinophil accumulation in small intra-parenchymal bronchi induced by OVA challenge of sensitised guinea pigs [43] while in a mouse model of asthma montelukast reversed allergen-induced airway remodelling [44].
In a recent study, we again used the Cellix VenaFlux ${ }^{\mathrm{TM}}$ platform to investigate the effects of montelukast on eosinophil adhesion under flow, demonstrating that physiologically relevant concentrations $(10 \mathrm{nM}$ and $100 \mathrm{nM})$ inhibited both resting and GM-CSF-stimulated eosinophil adhesion to VCAM-1 under flow conditions [45]. This effect appeared specific for montelukast as the analogue MK571 had no significant effect on eosinophil adhesion. The possibility that LTC4 released from unstimulated or GM-CSF-treated eosinophils contributed to their adhesion to VCAM-1 was excluded as the leukotriene biosynthesis inhibitor MK886 had no inhibitory effect and exogenously added LTC4 did not enhance eosinophil adhesion. In contrast, LTD4, enhanced eosinophil adhesion to VCAM-1; an effect blocked by montelukast. Inhibition of both resting and GM-CSF stimulated adhesion was observed at low, physiologically relevant concentrations of montelukast and was also observed at shear stress levels similar to that found in inflamed post-capillary venules i.e. 1-2 dyn $\mathrm{cm}^{-2}$. Although antagonism of the cysLT1R likely explains the majority of the antiinflammatory properties of leukotriene antagonists some effects may be independent of receptor blockade.

\section{TARGETING EOSINOPHIL-ACTIVE CYTOKINES AND CHEMOKINES}

\section{Interleukin-5}

Interleukin (IL)-5 is crucial to the development and release of eosinophils from the bone marrow, their enhanced adhesion to endothelial cells lining the post-capillary venules and their persistence, activation and secretion in the tissues. Several animal models of asthma including the use of primates have provided good evidence that inhibiting the effects of IL-5 using specific mAb inhibited eosinophilic inflammation and AHR [46]. Given its central role in regulating eosinophil development and function IL-5 was therefore chosen as a potentially attractive target to prevent or blunt eosinophil-mediated inflammation in patients with asthma. However, several clinical trials have reported disappointing clinical outcomes following treatment of asthmatic patients with an anti-IL-5 mAb. The first study was designed to validate the safety of the humaniszd anti-IL-5 mAb mepolizumab [47] leading to criticism of lack of power [48] and the validity of patient selection [49]. A later placebo-controlled study [50] found that treatment of mild asthmatic patients with mepolizumab abolished circulating eosinophils, reduced airway and bone marrow eosinophils but reported no significant improvement of clinical measures of asthma. Critically lung biopsy samples from the treatment group contained intact tissue eosinophils together with large quantities of eosinophil granule proteins, findings that likely explain the lack of clinical benefit following mepolizumab treatment. Similar findings were reported with the anti-IL-5 $\mathrm{mAb}$ SCH55700 in patients with severe asthma who had not been controlled by inhaled corticosteroid use. These authors reported profound reduction in circulating eosinophils, but no significant improvement in either asthma symptoms or lung function [51]. Importantly, compared with placebo, treatment of mild atopic asthmatics with mepolizumab significantly reduced the expression of the extracellular matrix proteins tenascin, lumican, and procollagen III in the bronchial mucosal reticular basement membrane together with significant reductions in both airway eosinophils expressing 
mRNA for TGF- $\beta 1$ and the concentration of TGF- $\beta 1$ in bronchoalveolar lavage (BAL) fluid [52]. TGF- $\beta 1$ is implicated in airway remodelling in asthma and eosinophils are important sources of this growth factor, thereby contributing to tissue remodelling processes in asthma by regulating the deposition of ECM proteins. Mepolizumab may prove useful in preventing this. An alternative to the use of humanised anti-IL-5 mAb is the use of molecular modelling of the IL-5 receptor $\alpha$-chain to develop specific receptor antagonists. Recently, such a compound (YM-90709) has been shown to be a relatively selective inhibitor of the IL-5R [53] and intravenous injection of YM-90709 inhibited infiltration of eosinophils into the BAL fluid of allergen-challenged BDF1 mice [54].

\section{Interleukin-4}

Another cytokine important in eosinophil accumulation is IL-4 and, together with its close relative IL-13, it is important in IgE synthesis by B cells. Both cytokines signal through a shared surface receptor, IL-4R $\alpha$, which then activates the transcription factor STAT-6 [55]. Studies with soluble IL-4R given in a nebulised form demonstrated that the fall in lung function induced by withdrawal of inhaled corticosteroids was prevented in patients with moderately severe asthma [56]. However, despite these promising findings subsequent trials have not been as successful and consequently this treatment is no longer being developed. Other approaches for blocking the IL-4 receptor include administration of antibodies against the receptor and mutant IL-4 proteins. For example, a peptide-based vaccine for blocking IL-4 was recently developed by antigenic prediction and structure analysis of the IL-4/receptor complex. Vaccine construction involved a truncated hepatitis B core antigen as carrier with the peptide inserted using gene engineering methods. Compared with control animals, allergenchallenged OVA-sensitised mice immunised with IL-4peptide vaccine had significant reductions in IgE, eosinophil accumulation in BAL, goblet cell hyperplasia, tissue inflammation and methacholine-induced respiratory responses [57].

\section{Interleukin-13}

IL-13 is thought to be a key mediator of asthma; for example it was significantly elevated in BAL following allergen provocation of asthmatic subjects, which strongly correlated with the increase in eosinophil numbers while mRNA expression for IL-13 was detected in bronchial biopsies from both allergic and non-allergic asthmatic subjects. In animal models, IL-13 mimics many of the pro-inflammatory changes associated with asthma $[58,59]$. It is therefore another potential therapeutic target for the resolution of airway inflammation. Two receptors for IL-13 have been described IL-13R $\alpha 1$ and IL-13R $\alpha 2$. The latter exists in soluble form and has a high affinity for IL-13 and can thus "mop up" secreted IL-13; in mice IL-13R $\alpha 2$ blocked the actions of IL13 , including IgE production, pulmonary eosinophilia and AHR [60]. A humanised IL-13R $\alpha 2$ is now in clinical development as a novel therapy for asthma [59]. Another mousebased study reported that intratracheal administration of human IL-13 induced leukocyte infiltration in the lung, AHR, and goblet cell metaplasia with allergic eosinophilic inflammation in the oesophagus. An anti-human IL-13 IgG4 mAb
(CAT-354) significantly reduced many of these parameters [61]. In contrast, another study using mice sensitised by intranasal application of ovalbumin as a model of asthma/allergy found that the inhibition of the IL-4/IL-13 system efficiently prevented the development of the asthmatic phenotype, including goblet cell metaplasia and airway responsiveness to methacholine, but had little effect on established asthma [62]. A humanised anti-IL-13 mAb IMA638 - significantly reduced eosinophils, neutrophils, eotaxin and RANTES in BAL fluid following segmental antigen challenge of cynomolgus monkeys sensitised to Ascaris suum, compared with levels seen in control animals [63]. IMA-638 also gave dose-dependent inhibition of the antigen-induced late responses and airway hyperresponsiveness in a sheep model of allergic asthma that utilised animals with natural airway hypersensitivity to Ascaris suum antigen [64].

\section{Interleukin-9}

Another TH2 cytokine, IL-9, and its receptor are found in asthmatic airways in increased levels [65]. IL-9 has several pro-inflammatory effects on eosinophils, including enhancement of eosinophil IL-5 receptor expression, differentiation in the bone marrow and prolonged survival through inhibition of apoptosis [66]. Transgene expression of IL-9 in the lungs of mice resulted in lymphocytic and eosinophilic infiltration of the lung, airway epithelial hypertrophy with mucus production, mast cell hyperplasia and production of IL-4, IL-5 and IL-13 [67]. One study examined the effect of anti-IL-9 antibody in OVA-sensitised BALB/c mice given 30 minutes before an aerosolised OVA-challenge. Compared with a control antibody, IL-9 antibody treatment was associated with reductions in BAL levels of eosinophils, AHR and IL-4, IL-5 or IL-13 [68].

\section{Eotaxin}

Chemokines are a family of small, secreted proteins that control migration of monocytes, lymphocytes, neutrophils, eosinophils, and basophils. Eotaxin, an inducible, secreted chemokine that promotes selective recruitment of eosinophils from the blood into inflammatory tissues was first described in 1993 when intradermal injection of naive guinea pigs with BAL fluid from antigen-challenged guinea pigs resulted in the recruitment of eosinophils [69]. Uniquely, the major characteristic of eotaxin is its selective ability to act on eosinophils. CCR3, a seven-transmembrane-spanning G protein-coupled receptor for eotaxin-1, is highly expressed on eosinophils and also mediates the biological effects of other eosinophil chemokines, such as eotaxin-2, eotaxin-3, MCP3, MCP-4, and RANTES. Furthermore, CCR3 is expressed not only on eosinophils but also on basophils [70], mast cell subpopulations [71] and activated Th2 cells [72], which might explain the coordinated recruitment of these cell types to sites of allergic inflammation. CCR3 is also expressed by airway epithelial cells [73], and although the bronchial epithelium consists of structural non-migratory cells, expression of the CCR3 receptor may represent an auto-regulatory feedback mechanism to monitor chemokine production. Furthermore, eotaxin produced by the epithelium may be sequestered by the CCR3 receptor and presented to infiltrating cells thereby enhancing their activation, a phenomenon observed with IL-8 and its receptor. Several clinical studies 
Table 1. Key Targets for Inhibition of Eosinophil Accumulation

\begin{tabular}{|c|c|c|c|}
\hline Compound & Target & Animal or In Vitro Studies & Clinical Outcome in Asthma \\
\hline ТВC 1269 & $\begin{array}{l}\text { Pan-selectin } \\
\text { inhibitor }\end{array}$ & $\begin{array}{l}\text { Mouse, rat, rabbit, GP and sheep models of allergic asthma } \\
{[15,16]}\end{array}$ & $\begin{array}{l}\text { Minor effect on sputum eosinophils and LAR } \\
\text { (intravenous) [17]. Inhaled - reduced LAR } \sim 50 \% \\
{[18]}\end{array}$ \\
\hline $\begin{array}{l}\alpha 4 \beta 1(\text { VLA-4) } \\
\text { mAb; SMA }\end{array}$ & Integrin & $\begin{array}{l}\text { Mouse, rat, rabbit, GP and sheep models of allergic asthma } \\
{[19-21]}\end{array}$ & $\begin{array}{l}\text { Oral SMA valategrast - positive effects on LF and } \\
\text { ER in asthmatics whose inhaled GC withdrawn } \\
\text { [22] }\end{array}$ \\
\hline Levocetirizine & $\begin{array}{l}\text { H1-receptor } \\
\text { antagonist }\end{array}$ & $\begin{array}{l}\text { No animal studies -significant inhibitory effect on human } \\
\text { eosinophil adhesion and TEM }[27,28]\end{array}$ & $\begin{array}{l}\text { Improved symptoms, QoL and reduced nasal } \\
\text { eosinophils in rhinitis patients with or without } \\
\text { asthma [29] }\end{array}$ \\
\hline Montelukast & $\begin{array}{l}\text { cysLT1R } \\
\text { antagonist }\end{array}$ & $\begin{array}{l}\text { Reduced eosinophils in GP lungs; reversed allergen-induced } \\
\text { AR in sensitised mice [43, 44]. Inhibited eosinophil TEM [ } 39 \text {, } \\
40] \text { and adhesion to VCAM-1 under flow [45] }\end{array}$ & $\begin{array}{l}\text { Some asthmatic subjects show a striking im- } \\
\text { provement and a steroid-sparing effect has been } \\
\text { demonstrated [34-36] }\end{array}$ \\
\hline $\begin{array}{l}\text { Anti-IL-5 } \\
\text { mAb; SMA }\end{array}$ & IL-5 & $\begin{array}{l}\text { Specific } \mathrm{mAb} \text { inhibited eosinophilic inflammation and AHR } \\
\text { in animals including primates }\end{array}$ & $\begin{array}{l}\text { No significant improvement of clinical measures } \\
\text { of asthma [47-51]. May prevent AR in asthmatics } \\
\text { [52] }\end{array}$ \\
\hline $\begin{array}{l}\text { Anti-IL-4 } \\
\text { mAb; anti-IL-4R; } \\
\text { mutant proteins }\end{array}$ & IL-4 & $\begin{array}{l}\text { IL-4-peptide vaccine reduced, BAL eosinophils, goblet cell } \\
\text { hyperplasia, inflammation and AHR in challenged OVA- } \\
\text { sensitised mice [57] }\end{array}$ & $\begin{array}{l}\text { Nebulised IL-4R positive effects on LF in moder- } \\
\text { ately severe asthmatics whose inhaled GC with- } \\
\text { drawn [56] }\end{array}$ \\
\hline $\begin{array}{l}\text { Anti-IL-13 } \\
\text { mAb; }\end{array}$ & IL-13 & $\begin{array}{l}\text { Humanised mAb effective in mouse asthma models }[60,61] \\
\text { reduced BAL eosinophils, eotaxin and RANTES in cynomol- } \\
\text { gus monkeys sensitised to Ascaris suum [63]. Reduced LAR } \\
\text { in sheep model of allergic asthma [64] }\end{array}$ & $\begin{array}{l}\text { Humanised IL-13R } \alpha 2 \text { in clinical development } \\
\text { [59] }\end{array}$ \\
\hline $\begin{array}{l}\text { Eotaxin } \\
\text { SMA }\end{array}$ & CCR3 & $\begin{array}{l}\text { CCR3 antagonism inhibited eotaxin-induced eosinophil Ca2+ } \\
\text { influx, chemotaxis and degranulation [75-77]. Inhibited eosi- } \\
\text { nophil infiltration into cynomolgus monkey airways after } \\
\text { eotaxin bronchoprovocation [77]. Reduced eosinophils, AHR } \\
\text { and AR in lungs of aerosol-challenged mice chronically sensi- } \\
\text { tised with OVA [78]. }\end{array}$ & \\
\hline
\end{tabular}

Abbreviations: SMA: small molecule antagonist LAR: late asthmatic reaction; LF: lung function; ER: exacerbation rate; AR: airway remodelling; GP: guinea pig; GC: glucocorticoid; QoL: quality of life; OVA: ovalbumin.

have suggested a pivotal role for CCR3 ligands/CCR3 in the eosinophilic inflammation characteristic of atopic dermatitis, asthma, and allergic rhinitis, thus blockade of this receptor may have pronounced beneficial effects in these diseases [74]. A number of small molecule CCR3 antagonists have been described. In this regard $\mathrm{N}$-(ureidoalkyl)benzpiperidines have been identified as potent CCR3 antagonists, inhibiting eosinophil chemotaxis and calcium mobilisation in the micro- to nanomolar concentration range [75]. The small molecule selective CCR3 antagonist, YM344031 , potently inhibited the binding of eotaxin-1 and RANTES to human cells transfected with CCR3, ligandinduced $\mathrm{Ca}^{2+}$ flux and chemotaxis together with inhibition of eotaxin-1-induced eosinophil shape change. Furthermore, both immediate- and late-phase allergic skin reactions in a mouse model were significantly inhibited by orally administered YM-344031 [76]. Another small molecule selective CCR3 antagonist YM-355179 inhibited eotaxin-induced intracellular $\mathrm{Ca} 2+$ influx, chemotaxis, and eosinophil degranulation. It also inhibited eosinophil infiltration into airways of cynomolgus monkeys after segmental bronchoprovocation with eotaxin [77]. The effect of a low-molecularweight CCR-3 antagonist on chronic experimental bronchial asthma was examined using BALB/c mice intraperitoneally sensitised with OVA subsequently chronically challenged with OVA aerosol to induce chronic airway inflammation and airway remodelling. CCR-3 antagonist treatment resulted in a marked reduction of eosinophils in the bronchoal- veolar lumen and in airway wall tissue, whereas infiltration of lymphocytes or macrophages remained unchanged. Furthermore, antagonising CCR-3 reduced AHR, goblet cell hyperplasia and airway remodelling as defined by subepithelial fibrosis and increased accumulation of myofibroblasts in the airway wall of chronically challenged mice. Therefore, antagonising CCR-3 may represent a novel approach to a promising asthma or allergy therapy [78]. Furthermore, there is evidence from animal models that IL-5 and eotaxin may work in a synergistic fashion to promote the release of mature eosinophils from the bone marrow [79]. Thus it might be that combination therapies of CCR3 antagonist and humanised anti-IL-5 mAb might prove an effective approach to limit or prevent eosinophil toxicity in the asthmatic lung.

\section{CONCLUSION}

Our understanding of the complex processes controlling eosinophil accumulation is now considerable and this knowledge has informed the development of several strategies aimed at blunting eosinophil accumulation. Overall there have been a considerable number of disappointing outcomes as several new therapies had little or no impact on clinical asthma despite the great initial promise seen in animal models of asthma. The recent positive outcomes in Phase II clinical trials in asthmatic patients with the smallmolecule selectin antagonist (bimosiamose) or integrin $\alpha 4 \beta 1$ small-molecule antagonist (valategrast) do provide evidence that novel strategies to treat asthma may yet be forthcoming. 
However, one important consideration is that potential side effects of targeting adhesion pathways as therapeutic avenues should always be considered as demonstrated by the recently reported series of fatal central nervous systems infections occurring during systemic treatment with the $\alpha 4 \beta 1$ antagonist natalizumab [80].

\section{ACKNOWLEDGEMENTS}

My work quoted in this review was supported by an unrestricted Medical School Grant from Merck \& Co., Inc., New Jersey, U.S.A., UCB Pharma Sa, Brussels, Belgium, Tenovus Scotland and a FP6-2004-Mobility3 Marie Curie grant, "ASTHMA"; contract number: MTKI-CT-2005029541.

\section{REFERENCES}

[1] Bousquet J, Chanez P, Lacoste JY, et al. Eosinophilic inflammation in asthma. N Engl J Med 1990; 323: 1033-9.

[2] Walsh GM, Al-Rabia M, Blaylock MG, Sexton DW, Duncan CJ. Lawrie A. Control of eosinophil toxicity in the lung. Curr Drug Targets Inflamm Allergy 2005; 4: 481-86

[3] Wenzel SE, Schwartz LB, Langmac EL, et al. Evidence that severe asthma can be divided pathologically into two inflammatory subtypes with distinct physiologic and clinical characteristics. Am J Respir Crit Care Med 1999; 160: 1001-8.

[4] Balzar S, Chu HW, Silkoff P, et al. Increased TGF-beta2 in severe asthma with eosinophilia J Allergy Clin Immunol 2005; 115: 110.

[5] Lee JJ, Dimina D, Macias MP, et al. Defining a link with asthma in mice congenitally deficient in eosinophils. Science 2004; 305 : 1773-6.

[6] Humbles AA, Lloyd CM, McMillan SJ, et al. A critical role for eosinophils in allergic airways remodelling. Science 2004; 305 : 1776-9.

[7] Ochkur SI, Jacobsen EA, Protheroe C, et al. Is Eosinophil Dependence of Pulmonary Allergic Inflammation in Mice Really Strain Specific? J Allergy Clin Immunol 2008; 121: Abstract LB5.

[8] MacKenzie JR, Mattes J, Dent LA, Foster PS. Eosinophils promote allergic disease of the lung by regulating CD4 + Th2 lymphocyte function. J Immunol 2001; 167: 3146 .

[9] Wang H-B, Ghiran I, Matthaei K, Weller PF. Airway eosinophils: allergic inflammation recruited professional antigen-presenting cells. J Immunol 2007; 179: 7585-92.

[10] Yang D, Rosenberg HF, Chen Q, Dyer KD, Kurosaka K, Oppenheim JJ. Eosinophil-derived neurotoxin (EDN), an antimicrobial protein with chemotactic activities for dendritic cells. Blood 2003; 102: 3396 .

[11] Yang D, Chen Q, Su SB, et al. Eosinophil-derived neurotoxin acts as an alarmin to activate the TLR2-MyD88 signal pathway in dendritic cells and enhances Th2 immune responses. J Exp Med 2008; 205: 79-90.

[12] Jacobsen EA, Ochkur SI, Pero RS, et al. Allergic pulmonary inflammation in mice is dependent on eosinophil-induced recruitment of effector T cells. J Exp Med 2008; 205: 699-710.

[13] Walsh GM. Advances in the immunobiology of eosinophils and their role in disease. Crit Rev Clin Lab Sci 1999; 36: 453-96.

[14] Vanderslice P, Biediger RJ, Woodside DG, Berens KL, Holland GW, Dixon RA. Development of cell adhesion molecule antagonists as therapeutics for asthma and COPD. Pulm Pharmacol Ther 2004; 17: 1-10.

[15] Kogan TP, Dupre B, Bui H, et al. Novel synthetic inhibitors of selectin-mediated cell adhesion: synthesis of 1,6-bis[3-(3carboxymethylphenyl)-4-(2-alpha-D- mannopyranosyloxy)phenyl] hexane (TBC1269). J Med Chem 1998; 41: 1099-1111.

[16] Abraham WM, Ahmed A, Sabater JR, et al. Selectin blockade prevents antigen-induced late bronchial responses and airway hyperresponsiveness in allergic sheep. Am J Respir Crit Care Med 1999; 159: 1205-14.

[17] Avila PC, Boushey HA, Wong H, Grundland H, Liu J, Fahy JV. Effect of a single dose of the selectin inhibitor TBC1269 on early and late asthmatic responses. Clin Exp Allergy 2004; 34: 77-84.

[18] Beeh KM, Beier J, Buhl R, Zahlten R, Wolff G. Influence of inhaled Bimosiamose (TBC1269), a synthetic pan-selectin antagonist, on the allergen-induced late asthmatic response (LAR) in pa- tients with mild allergic asthma. Am J Respir Crit Care Med 2004; 169: A321.

[19] Henderson WR, Chi EY, Albert RK, et al. Blockade of CD49d (alpha4 integrin) on intrapulmonary but not circulating leukocytes inhibits airway inflammation and hyperresponsiveness in a mouse model of asthma. J Clin Invest 1997; 100: 3083-92.

[20] Sedgwick JB, Jansen KJ, Kennedy JD, Kita H, Busse WW. Effects of the very late adhesion molecule 4 antagonist WAY103 on human peripheral blood eosinophil vascular cell adhesion molecule 1dependent functions. J Allergy Clin Immunol 2005; 116: 812-19.

[21] Okigami H, Takeshita K, Tajimi M, et al. Inhibition of eosinophilia in vivo by a small molecule inhibitor of very late antigen (VLA)-4. Eur J Pharmacol 2007; 559: 202-9.

[22] Woodside DG, Vanderslice P. Cell adhesion antagonists: therapeutic potential in asthma and chronic obstructive pulmonary disease. BioDrugs 2008; 22: 85-100.

[23] Leurs R, Church MK, Taglialatela M. H1-antihistamines: inverse agonism, anti-inflammatory actions and cardiac effects. Clin Exp Allergy 2002; 32: 489-98.

[24] Simons FE. Advances in H1-antihistamines. N Engl J Med 2004; 351: 2203-17.

[25] Walsh GM, Annunziatto L, Frossard N, et al. New insights into the second generation antihistamines. Drugs 2001; 61: 207-36.

[26] Walsh GM. A review of the role of levocetirizine as an effective therapy for allergic disease. Expert Opin Pharmacother 2008; 9: 859-67.

[27] Thomson L, Blaylock MG, Sexton DW, Campbell A, Walsh GM Cetirizine and levocetirizine inhibit eotaxin-induced eosinophil transendothelial migration through human dermal or lung microvascular endothelial cells. Clin Exp Allergy 2002; 32: 1187-92.

[28] Wu P, Mitchell S, Walsh GM. A new antihistamine levocetirizine inhibits eosinophil adhesion to vascular cell adhesion molecule-1 under flow conditions. Clin Exp Allergy 2005; 35: 1073-9.

[29] Pasquali M, Baiardini I, Rogkakou A, et al. Levocetirizine in persistent allergic rhinitis and asthma: effects on symptoms, quality of life and inflammatory parameters. Clin Exp Allergy 2006; 36: 1161-7.

[30] Menzies-Gow A, Ying S, Phipps S, Kay AB. Interactions between eotaxin, histamine and mast cells in early microvascular events associated with eosinophil recruitment to the site of allergic skin reactions in humans. Clin Exp Allergy 2004; 34: 1276.

[31] Giustizieri ML, Albanesi C, Fluhr J, Gisondi P, Norgauer J, Girolomoni G. H1 histamine receptor mediates inflammatory responses in human keratinocytes. J Allergy Clin Immunol 2004; 114: 1176-82.

[32] Petecchia L, Serpero L, Silvestri M, Sabatini F, Scarso L, Rossi GA. The histamine-induced enhanced expression of vascular cell adhesion molecule-1 by nasal polyp-derived fibroblasts is inhibited by levocetirizine. Am J Rhinol 2006; 20: 445-9.

[33] Hasala H, Janka-Junttila M, Moilanen E, Kankaanranta H. Levocetirizine and cytokine production and apoptosis of human eosinophils. Allergy Asthma Proc 2007; 28: 582-91.

[34] Pizzichini E, Leff JA, Reiss TF, et al. Montelukast reduces airway eosinophilic inflammation in asthma: a randomised, controlled trial. Eur Respir J 1999; 14: 12-18.

[35] Palmqvist M, Bruce C, Sjostrand M, Arvidsson P, Lotvall J. Differential effects of fluticasone and montelukast on allergen-induced asthma. Allergy 2005; 60: 65-70.

[36] Nayak P. A review of montelukast in the treatment of asthma and allergic rhinitis. Expert Opin Pharmacother 2004; 5: 679-86.

[37] Devillier P, Baccard N, Advenier C. Leukotrienes, leukotriene receptor antagonists and leukotriene synthesis inhibitors in asthma: an update. Part I: synthesis, receptors and role of leukotrienes in asthma. Pharmacol Res 1999; 40: 3-13.

[38] Nagata M, Saito K, Tsuchiya K, Sakamoto Y. Leukotriene D4 upregulates eosinophil adhesion via the cysteinyl leukotriene 1 receptor. J Allergy Clin Immunol 2002; 109: 676-80.

[39] Virchow Jr JC, Faehndrich S, Nassenstein C, Bock S, Matthys H, Luttman W. Effect of a specific cysteinyl leukotriene receptor antagonist (montelukast) on the transmigration of eosinophils across human umbilical vein endothelial cells. Clin Exp Allergy 2001; 31: 836-44.

[40] Saito K, Nagata M, Kikuchi I, Sakamoto Y. Leukotriene D4 and eosinophil transendothelial migration, superoxide generation, and degranulation via beta2 integrin. Ann Allergy Asthma Immunol 2004; 93: 594-600. 
[41] Nagata M, Saito K, Kikuchi I, Hagiwara K, Kanazawa M. Effect of the cysteinyl leukotriene antagonist pranlukast on transendothelial migration of eosinophils. Int Arch Allergy Immunol 2005; 137: 26.

[42] Meliton AY, Munoz NM, Leff AR. Blockade of avidity and focal clustering of beta 2-integrin by cysteinyl leukotriene antagonism attenuates eosinophil adhesion. J Allergy Clin Immunol 2007; 120 : 1316-23.

[43] Harrison S, Gatti R, Baraldo S, et al. Montelukast inhibits inflammatory responses in small airways of the Guinea-pig. Pulm Pharmacol Ther 2008; 21(2): 317-23.

[44] Henderson Jr WR, Chiang GK, Tien YT, Chi EY. Reversal of allergen-induced airway remodelling by CysLT1 receptor blockade. Am J Respir Crit Care Med 2005; 173: 718-28.

[45] Robinson AJ, Kashanin D, O’Dowd F, Williams V, Walsh GM. Montelukast inhibition of resting and GM-CSF-stimulated eosinophil adhesion to VCAM-1 under flow conditions appears independent of CysLT1 antagonism. J Leuk Biol 2008; 83: 1522-9.

[46] Egan RW, Umland SP, Cuss FM, Chapman RW. Biology of interleukin-5 and its relevance to allergic disease. Allergy 1996; 51: 7181.

[47] Leckie MJ, ten Brinke A, Khan J, et al. Effects of an interleukin-5 blocking monoclonal antibody on eosinophils, airway hypersonsiveness and the late asthmatic response. Lancet 2000; 356: 2144-8.

[48] O'Byrne PM, Inman MD, Parameswaran K. The trials and tribulations of IL-5, eosinophils and allergic asthma. J Allergy Clin Immunol 2001; 108: 503-8.

[49] Lipworth BJ. Eosinophils and airway hyper-responsiveness. Lancet 2001; 357: 1446.

[50] Flood-Page PT, Menzies-Gow AN, Kay AB, Robinson D. Eosinophil's role remains uncertain as anti-interleukin-5 only partially depletes numbers in asthmatic airway. Am J Respir Crit Care Med 2003; 167: 199.

[51] Kips JC, O’Conner BJ, Langley SJ, et al. Effect of SCH55700, a humanised anti-human interleukin-5 antibody in severe persistent asthma - a pilot study. Am J Resp Crit Care Med 2003; 167: 16559.

[52] Flood-Page P, Menzies-Gow A, Phipps S, et al. Anti-IL-5 treatment reduces deposition of ECM proteins in the bronchial subepithelial basement membrane of mild atopic asthmatics. J Clin Invest 2003; 112: 1029-36.

[53] Morokata T, Ida K, Yamada T. Characterization of YM-90709 as a novel antagonist which inhibits the binding of interleukin-5 to interleukin-5 receptor. Int Immunopharmacol 2002; 2: 1693-1702.

[54] Morokata T, Suzuki K, Ida K, Yamada T. Effect of a novel interleukin-5 receptor antagonist, YM-90709, on antigen-induced eosinophil infiltration into the airway of BDF1 mice. Immunol Lett 2005; 98:161-5.

[55] Jiang H, Harris MB, Rothman P. IL-4/IL-13 signalling beyond JAK/STAT. J Allergy Clin Immunol 2000; 105: 1063-70.

[56] Borish LC, Nelson HS, Lanz MJ, et al. Interleukin-4 receptor in moderate atopic asthma. A phase I/II randomised, placebocontrolled trial. Am J Respir Crit Care Med 1999; 160: 1816-23.

[57] Ma Y, Hayglass KT, Becker AB, et al. Novel cytokine peptidebased vaccines: an interleukin-4 vaccine suppresses airway allergic responses in mice. Allergy 2007; 62: 675-82.

[58] Wills-Karp M, Luyimbazi J, Xu X, et al. Interleukin-13: central mediator of allergic asthma. Science 1998; 282: 2258-60.

[59] Walsh GM, McDougall CM. The resolution of airway inflammation in asthma and COPD. In: Progress in Inflammation Research Eds. A.G. Rossi and D. Sawatzky, Birkhauser Verlag AG, 2008; 159-91.

[60] Chiaramonte MG, Mentink-Kane M, Jacobson BA, et al. Regulation and function of the interleukin 13 receptor alpha 2 during a $\mathrm{T}$ helper cell type 2-dominant immune response. J Exp Med 2003; 197: 687-701.
[61] Blanchard C, Mishra A, Saito-Akei H, Monk P, Anderson I, Rothenberg ME. Inhibition of human interleukin-13-induced respiratory and oesophageal inflammation by anti-human-interleukin-13 antibody (CAT-354). Clin Exp Allergy 2005; 35: 1096-1103.

[62] Hahn C, Teufel M, Herz U, et al. Inhibition of the IL-4/IL-13 receptor system prevents allergic sensitization without affecting established allergy in a mouse model for allergic asthma. J Allergy Clin Immunol 2003; 111: 1361-9.

[63] Bree A, Schlerman FJ, Wadanoli M, et al. IL-13 blockade reduces lung inflammation after Ascaris suum challenge in cynomolgus monkeys. J Allergy Clin Immunol 2007; 119: 1251-7.

[64] Kasaian MT, Donaldson DD, Tchistiakova L, et al. Efficacy of IL13 neutralization in a sheep model of experimental asthma. Am J Respir Cell Mol Biol 2007; 36: 368-76.

[65] Shimbara A, Christodoulopoulos P, Soussi-Gounni A, et al. IL-9 and its receptor in allergic and nonallergic lung disease: increased expression in asthma. J Allergy Clin Immunol 2000; 105: 108-115.

[66] Gounni AS, Gregory B, Nutku E, et al. Interleukin-9 enhances interleukin-5 receptor expression, differentiation, and survival of human eosinophils. Blood 2000; 96: 2163.

[67] Temann U-A, Ray P, Flavell RA. Pulmonary overexpression of IL9 induces Th2 cytokine expression, leading to immune pathology $\mathrm{J}$ Clin Invest 2002; 109: 29-39.

[68] Cheng G, Arima M, Honda K, et al. Anti-interleukin-9 antibody treatment inhibits airway inflammation and hyperreactivity in mouse asthma model. Am J Respir Crit Care Med 2002; 166: 40916.

[69] Griffiths-Johnson DA, Collins PD, Rossi AG, et al. The chemokine, eotaxin, activates guinea pig eosinophils in vitro and causes their accumulation in the lung in vivo. Biochem Biophys Res Commun 1993; 197: 881-7.

[70] Uguccioni M, Mackay CR, Ochensberger B, et al. High expression of the chemokine receptor CCR3 in human blood basophils. Role in activation by eotaxin, MCP-4, and other chemokines. J Clin Invest 1997; 100: 1137-43.

[71] Romagnani P, De Paulis A, Beltrame C, et al. Tryptase-chymase double-positive human mast cells express the eotaxin receptor CCR3 and are attracted by CCR3-binding chemokines. Am J Pathol 1999; 155: 1195-1204.

[72] Sallusto F, Mackay CR, Lanzavecchia A. Selective expression of the eotaxin receptor CCR3 by human T helper 2 cells. Science 1997; 277: 2005-7.

[73] Stellato C, Brummet ME, Plitt JR, et al. Expression of the C-C chemokines receptor CCR3 in human airway epithelial cells. J Immunol 2001; 166: 1457-61.

[74] Erin EM, Williams TJ, Barnes PJ, Hansel TT. Eotaxin receptor (CCR3) antagonism in asthma and allergic disease. Curr Drug Targets Inflamm Allergy 2002; 1: 201-14.

[75] De Lucca GV, Kim UT, Johnson C, et al. Discovery and structureactivity relationship of $\mathrm{N}$-(ureidoalkyl)-benzyl-piperidines as potent small molecule CC chemokine receptor-3 (CCR3) antagonists. J Med Chem 2002; 45: 3794-3804.

[76] Suzuki K, Morokata T, Morihira K, et al. In vitro and in vivo characterization of a novel CCR3 antagonist, YM-344031. Biochemical and Biophysical Research Communications 2006; 339: 1217-23.

[77] Morokata T, Suzuki K, Masunaga Y, et al. A novel, selective, and orally available antagonist for CC chemokine receptor 3. J Pharmacol Exp Ther 2006; 317: 244-50.

[78] Wegmann M, Göggel R, Sel S, et al. Effects of a low-molecularweight CCR-3 antagonist on chronic experimental asthma. Am J Respir Cell Mol Biol 2007; 36: 61-7.

[79] Palframan RT, Collins PD, Williams TJ, Rankin SM. Eotaxin induces a rapid release of eosinophils and their progenitors from the bone marrow. Blood 1998; 91: 2240.

[80] Berger JR, Koralnik IJ. Progressive multifocal leukoencephalopathy and natalizumab - unforeseen consequences. $\mathrm{N}$ Engl J Med 2005; 353: 414-6. 